Departamento de História da PUC Ri R. Marquêsde SãoVicente, 225-alaFrings-sala 512 22451-900 - Rio de Janeiro - Rio de Janeiro crisalfagali@puc-rio.br

\section{CONFLITO DE TERRAS NOS SERTÕES DE} ANGOLA: ESTUDO DE CASO DA DISPUTA PELAS \section{TERRAS DE ILAMBA, SÉCULO XVIII*}

\section{- Crislayne Alfagali**}

Pontifícia Universidade Católica do Rio de Janeiro (PUC-Rio)

Rio de Janeiro - Rio de Janeiro - Brasil

\title{
Resumo
}

Este artigo analisa os conflitos de terra que decorreram da instalação de uma fábrica de ferro na região da Ilamba, no interior de Angola, na segunda metade do século XVIII. A desapropriação das terras africanas, na África Centro-Ocidental, em períodos anteriores ao século XIX, é uma temática pouco abordada pela historiografia. Este estudo de caso contribui para pensar a questão à medida que analisa os mecanismos coloniais de espoliação das terras e recursos naturais das lideranças africanas locais, considerando também as estratégias dos sobas para manter seu poder político ao longo do tempo.

\section{Palavras-chave}

Colonização - Angola - terras - autoridades africanas - conflitos.

* Todas as obras e todos os documentos utilizados na pesquisa e na elaboração do artigo são citados nas notas e na bibliografia. Agradeço aos avaliadores e revisores pelas críticas, sugestões e correções.

${ }^{* *}$ Graduada em História pela Universidade Federal de Ouro Preto (Ufop), mestre e doutora pela Universidade Estadual de Campinas (Unicamp). Professora assistente do Departamento de História e do Programa de Pós-Graduação em História Social da Cultura da Pontifícia Universidade Católica do Rio de Janeiro (PUC-Rio). 


\section{- Crislayne Alfagali}

Pontifícia Universidade Católica do Rio de Janeiro (PUC-Rio)

Rio de Janeiro - Rio de Janeiro - Brazil

\begin{abstract}
This paper analyzes the land tenure conflicts that resulted from the installation of an iron foundry in the region of Ilamba, in Angola hinterland, in the second half of the 18th century. The expropriation of African lands in West Central Africa in pre-nineteenth-century periods is a subject rarely addressed in historiography. This case study contributes to reflect on the issue, since it analyzes the colonial mechanisms of spoliation of lands and natural resources from the local African chiefdoms. On the other hand, the analysis also considers the sobas's strategies to maintain their political power over time.
\end{abstract}

\title{
Keywords
}

Colonization - Angola - land tenure - African chiefdoms - conflicts. 
A partir do século XVII, a problemática da territorialização do Império português passou a ser essencial na comunicação política ultramarina. O controle de espaços marítimos e de redes políticas e comerciais assentadas em alianças com as populações locais tornou-se insatisfatório. O império territorialmente descontínuo descrito por Luís Felipe Thomaz (1994) daria lugar a um novo paradigma alicerçado na territorialização. A ocupação da terra e a delimitação do território seriam então elementos fulcrais da colonização portuguesa (HESPANHA \& SANTOS, 1993).

A área sob influência lusa em parte das terras do antigo Reino do Ndongo, chamada de Reino de Angola, não foi uma exceção nesse processo. Nos séculos XVI e XVII, as campanhas militares e as incursões de missionários, funcionários coloniais e particulares, como negociantes ou sertanejos, possibilitaram conhecer os sertões de Luanda. ${ }^{1}$ Contudo, foi sobretudo na segunda metade do século XVIII que o espaço da colônia foi reavaliado, dentro dos planos reformistas do marquês de Pombal. O incentivo ao povoamento civil e à construção de novas vilas tinha por objetivo ordenar e controlar o espaço dentro de um programa de reformas que visavam ampliar a autoridade real no interior das colônias, aproveitando "ao máximo as potencialidades dos territórios até então inexplorados" ou pouco explorados (DELSON, 1997, p. 140). ${ }^{2}$

De forma geral, há um esforço de unificação do espaço no sentido de afirmar a soberania portuguesa por meio de uma ocupação política que tinha também por objetivo difundir valores europeus, pretensamente superiores, entre os súditos da Coroa, os "naturais da terra". Os planos coloniais encontraram diferentes formas de resistência a essas tentativas de dominação dos sertões e de suas gentes. No Reino de Angola, os programas de remodelação do interior se depararam com as lógicas locais de ocupação territorial.

No século XVIII, com a interiorização da presença portuguesa e a exploração local de recursos naturais, a relação com a posse linhageira da terra sofreu alterações importantes, como veremos no decorrer deste texto.

Desde os primeiros contatos intermediados pelo Reino do Kongo, o abastecimento dos navios para tráfico atlântico de escravos e a própria permanência dos estrangeiros nas terras do antigo Reino do Ndongo dependeram

\footnotetext{
MONTECÚCCOLO, Giovanni Antonio Cavazzi de. Descrição histórica dos três reinos do Congo, Matamba e Angola. Tradução, notas e índices do padre Graciano Maria de Leguzzano. Lisboa: Junta de Investigações do Ultramar, 1965.

2 Outra maneira de abordar a temática é por meio da análise de documentos cartográficos. Desde as primeiras décadas do Setecentos, os diplomatas europeus se dedicaram a legitimar a apropriação política dos territórios do ultramar (KANTOR, 2009).
} 
de alianças com as lideranças africanas e do trabalho de seus dependentes. Assim, a presença portuguesa no Reino de Angola, nos séculos XVII e XVIII, se sustentava por meio de acordos de vassalagem com os sobas vencidos em guerra ou de alianças com as chefias locais interessadas em acordos comerciais. Entre os líderes locais, os sobas foram os principais protagonistas das negociações com os portugueses, pois eram eles que determinavam quem poderia ter passagem por seus territórios, estabeleciam acordos comerciais e ajustavam os termos da cessão de trabalhadores escravos e livres, intermediando as relações com os poderes locais (CARVALHO, 2015; HEINTZE, 2007).

Os sobas eram os chefes locais sob domínio de reis africanos ou do rei de Portugal quando se tornavam vassalos da Coroa portuguesa. Segundo Vansina (2004, p. 196), sobas eram aqueles que ocupavam posições de liderança nos "chefados monocefálicos" (monocephalic chiefdom), que seriam os sobados. Outras autoridades dos Ambundos aparecem nas fontes portuguesas subordinadas ou associadas aos sobas: o conselheiro, o kota, o sobeta (sobas menores sob a jurisdição de um soba mais poderoso), além de outras autoridades com funções espirituais, bélicas e/ou políticas - o tandala, o ngolambole, o kimbanda. Existia também o kilamba, descrito por Virgílio Coelho (2010, p. 161) como um sacerdote "encarregado de aplacar a fúria dos gênios da natureza", mas ao que parece o significado deste título se alterou no decorrer do tempo devido à influência portuguesa, uma vez que os kilambas passaram a ser conhecidos pelos laços com os colonizadores.

Ao longo da ocupação portuguesa e das sucessivas guerras do século XVII que levaram à conquista do Ndongo, e devido a mudanças na política colonial, a correlação de forças entre africanos e portugueses foi se alterando. Algumas chefias sobreviveram e muitas outras sucumbiram diante da violência da conquista militar e das demandas do tráfico de escravos, enquanto novas emergiram.

No entanto, as alianças com as chefias locais foram uma constante durante todo o período. A conservação da presença portuguesa no Reino de Angola só se tornou possível devido à submissão das soberanias africanas. Por sua vez, o poder dos sobas se assentava no número de súditos sob seu domínio. Quanto mais dependentes, mais plantações (arimos) e mais alimentos teriam, assim como mais possibilidades de agregar novos súditos e riquezas. Desse modo, as chefias controlavam tanto terras e recursos naturais quanto a força de trabalho para explorá-los.

A exploração colonial que seguiu à conquista não aniquilou completamente a autonomia das lideranças locais. A sujeição dos sobas ao rei de Portugal, ainda que pressupondo uma reciprocidade assimétrica, permitia 
alguma margem de ação porque estava pautada na ideia de interdependência. Os estudiosos que têm se ocupado do assunto consideram que a história das relações políticas e econômicas dos sobados com os conquistadores revela uma trama complexa que passa da "colaboração à resistência", da "adaptação à rejeição" (DIAS, 1997, p. 15).

A relação dos Ambundos com o seu território estava vinculada a "complexos laços sobrenaturais [que] uniam cada grupo de parentesco às suas terras e integravam o povo e o território numa única coletividade" (MILLER, 1995, p. 239). ${ }^{3}$ A posse de um terreno era coletiva e, à medida que as colheitas esgotavam o solo das aldeias, novos campos eram abertos em um sistema de cultivo itinerante.

O movimento dos sobados, seguindo diretrizes sobrenaturais e/ou em busca de melhores terras para plantio, não se alinhava ao traçado fixo da cartografia portuguesa, afinal, eram duas concepções diferentes de ocupação territorial. Por isso, em 1797, o governador Miguel António de Melo indica falhas em um mapa de época:

Porquanto sendo as banzas ou aldeias dos negros fabricadas de casa de palha e mudando-as elas quase todos os dias de uns para outros sítios, e nunca pouco distante do deixado, todas as vezes que ou lhe apraz ou a isso são levados por seus agoiros, e superstições, o que na carta se notasse hoje povoado, amanhã se encontrará deserto, e cheio de mato habitado por feras. ${ }^{4}$

A resistência armada foi uma estratégia importante contra a espoliação do território africano pelos conquistadores. Contudo, não foi a única. Valendo-se de um acúmulo de experiência frente à colonização portuguesa e de práticas políticas próprias, as lideranças locais apresentaram súplicas e pareceres, enviaram cartas e firmaram acordos que garantiam a manutenção de seu poder linhageiro, procurando evitar a desagregação de seu povo, a perda de suas terras, riquezas e privilégios. ${ }^{5}$

\footnotetext{
3 Assim, por exemplo, os espíritos dos antepassados de uma linhagem só descansariam se os corpos dos mortos fossem enterrados nas terras da linhagem.

${ }^{4}$ ANTÓNIO DE MELO, Miguel. [Correspondência]. Destinatário: Rodrigo de Sousa Coutinho. São Paulo de Assunção de Luanda, 3 dez. 1797. Arquivo Histórico Ultramarino. AHU_CU_001, Cx. 86, D. 66.

5 Segundo Silvia Lara (2008, p. 232), houve um acúmulo de experiência política nas regiões ocupadas pelos portugueses. Essa experiência foi pautada por parâmetros europeus e, no caso, centro-africanos que possuíam uma "sintaxe política" própria, uma cultura política que ditou o modo como os africanos lidaram com os portugueses e outros europeus.
} 
Algo muito similar pode ser dito do processo de apropriação de terras indígenas na América portuguesa. A conquista desse território foi marcada por combates violentos contra os indígenas. Além disso, os aldeamentos foram mecanismos de controle das populações locais, de seus recursos naturais e do acesso à mão de obra. A criação de povoados fixos com uma delimitação territorial permanente era contrária aos elementos da organização social e cultural de diversas sociedades indígenas. Como ocorria entre os Ambundos em Angola, entre os indígenas, na outra margem do Atlântico, os deslocamentos de uma aldeia eram frequentes e respondiam a uma série de fatores, como o esgotamento de recursos naturais e conflitos entre lideranças políticas.

A resistência indígena por meio de guerras e ataques aos conquistadores foi fundamental para conter a expansão colonial. Todavia, os indígenas também apresentavam petições, tratados e acordos em que contestavam as novas definições do direito de propriedade e a restrição do uso da terra a áreas determinadas pelos colonizadores. ${ }^{6}$

Portanto, daquém e dalém mar as políticas coloniais de espoliação da terra das sociedades locais encontraram tipos variados de resistência, inclusive dentro das normas de uma diplomacia que combinava práticas políticas lusas e locais.

\section{As terras da Ilamba na documentação sobre a Fábrica de Ferro de Nova Oeiras}

A região da Ilamba tinha recursos valiosos para as sociedades centro-africanas, sendo importante por questões econômicas, mas não só por conta delas. A Ilamba Baixa era limitada a norte pelo rio Ndande e a leste pelos rios Luinha e o Lukala; a oeste, ia até cerca de $40 \mathrm{~km}$ a leste de Luanda e à lagoa da Kilunda (situada na margem esquerda do rio Mbengu), ou seja, quase até a Costa Atlântica. Essa província, que aparece registrada nas fontes escritas em 1586, foi a primeira a ser conquistada pelos portugueses, que a chamavam de "Ilamba nossa". Seu chefe mais importante foi Mubanga, da linhagem do Ndongo. ${ }^{7}$

\footnotetext{
6 Sobre a questão da terra indígena, das guerras coloniais e da resistência indígena, ver Almeida (2003); Monteiro (1994), primeiro capítulo; Puntoni (2002); e Ricupero (2009), capítulos 8 e 9.

7 Cf. Freudenthal e Pantoja (2013, p. 47), Heintze (2007, p. 192-193), Ito (2016, p. 81), Montecúccolo (1965, v. I, p. 33).
} 
Na Ilamba, os chefados mineravam o ferro muito antes das iniciativas portuguesas de exploração deste mineral e, não por acaso, ali foram assentadas as fábricas de ferro de Nova Oeiras e Novo Belém (em meados da década de 1760). O acesso a este recurso, bem como às salinas, valorizava as terras, que foram alvo de disputas entre os próprios sobas e entre eles e outros súditos da Coroa portuguesa (MILLER, 1965, p. 267).

Quando o governo de Luanda resolveu instalar fábricas de ferro na região, os embates se manifestaram inicialmente por meio de querelas pela posse de terras. É evidente que o governo de Luanda precisaria de parte das minas da região, que eram controladas pelas autoridades locais. Além das minas, o governador planejou que uma parcela das terras onde fundou a povoação de Nova Oeiras fosse utilizada para hortas para a subsistência dos trabalhadores da fábrica e dos serviços auxiliares. ${ }^{8}$

Por meio da leitura da documentação, é possível identificar as terras de alguns sobas na vizinhança mais próxima do lugar escolhido para as fábricas: Nguengue a Kimbemba, dono de minas de ferro - "o qual soba vai confinar com outro", Kyambata kya Ngoto. "E indo-se circulando só na distância de dez ou doze léguas (aproximadamente $50 \mathrm{~km}$ ) se acham os sobas seguintes": Itombe ya KaNdongo, Nzambi a Keta, Ngola a Kiato, Ngolome, Kabuku Kambilu, Kisala kya Kabuku, Nzamba Nsungui, Kabuto e Kilamba Pedro Ambaxi. Essa relação foi feita pelo capitão Joaquim de Sousa Lobo em uma missão encomendada pelo governador Francisco de Sousa Coutinho.

A descrição mostra que o funcionário percebia as divisões entre as terras dos chefados africanos. O governador Sousa Coutinho chegou a afirmar essa percepção em cartas da governadoria de janeiro de 1767, quando disse que a fábrica que se instalou no Luinha ficava no "terreno" do soba Nguengue a Kimbemba. A fábrica do Novo Belém, no coração da Ilamba Baixa, ficava no "terreno" do Kilamba Ngongue a Kamukala. ${ }^{10}$ Ou seja: as fábricas

\footnotetext{
8 Dizia o governador sobre as terras da região: “Como me dizem que do rio Luinha, onde há de ser a Nova Oeiras, até a feira do Zundo, há terras admiráveis, estenderá as povoações e as sementeiras por todas elas, estando baldias" (COUTINHO, 1767a).

9 COUTINHO, Francisco Inocêncio de Sousa. Instrução que levou o capitão Joaquim de Sousa Lobo. São Paulo de Assunção de Luanda, 18 jul. 1768b. Instituto de Estudos Brasileiros/USP. Coleção Alberto Lamego, AL-083-099.

${ }^{10}$ COUTINHO, Francisco Inocêncio de Sousa. Instrução que deve guardar Antonio Anselmo Duarte de Siqueira servindo o emprego de intendente geral da Fábrica do Ferro e que executaram também os capitães mores como intendentes particulares na parte que lhes é respectiva. Destinatário: Antonio Anselmo Duarte de Siqueira. São Paulo de Assunção de Luanda, 12 jan. 1767a. Arquivo Histórico Ultramarino. AHU_CU_001, Cx. 52, D. 73.
} 
foram instaladas em áreas que pertenciam, no sentido político e econômico, a esses sobas e ilamba (kilamba no singular, ilamba no plural $\left.{ }^{11}\right) .{ }^{12}$

Um registro de fevereiro de 1767, dois anos após o início da construção das fábricas, informa que a posse de terras na região foi reclamada pelos sobas que estavam sob a jurisdição do capitão-mor do presídio de Muxima. Naquele ano, o sargento-mor do presídio escreveu sobre conflitos entre moradores e sobas de Muxima quanto à "pertenção (sic) das terras aonde se assenta a fábrica". Os moradores diziam ter comprado aqueles terrenos dos sobas, que por seu turno os acusavam de tê-los roubado. O governador ordenou que o intendente-geral das fábricas de ferro desconsiderasse essas querelas e desse ouvidos apenas a quem apresentasse os documentos comprobatórios da propriedade, requerendo os papéis de venda porque não estava seguro de que "os sobas pod[iam] ou não vender as terras do seu estado". ${ }^{13}$ Essa é a primeira menção, no contexto de construção da fábrica, à ideia de que a terra Ambunda não poderia ser negociada. Havia, portanto, outras regras, não ignoradas pelos portugueses, que regiam a relação dos centro-africanos com seu território.

O assunto não se esgotou nesse evento. Em abril de 1767, o intendente das fábricas escreveu ao governador sugerindo que a povoação de Nova Oeiras se fixasse junto à banza do soba Muxixi, que ficava às margens do rio Lukala. O governador respondeu que isso não seria proveitoso, desaprovando a ideia do funcionário. ${ }^{14}$ Não é de espantar que um ano depois o soba Muxixi tenha reclamado as "terras do Luinha".15 Muito provavelmente, o intendente avançou a ocupação até as terras do soba, mesmo sem a aprovação do governo de Luanda. Para além da questão da terra, observam-se aqui tensões que perpassam a história do Reino de Angola: as altercações entre o governo de Luanda e os agentes coloniais dos sertões.

\footnotetext{
${ }^{11}$ Nas línguas bantu o plural das palavras é na maioria das vezes formado pelo acréscimo de um prefixo.

${ }^{12}$ COUTINHO, $1768 \mathrm{~b}$.

${ }^{13}$ COUTINHO, Francisco Inocêncio de Sousa. [Correspondência]. Destinatário: Antonio Anselmo Duarte de Siqueira. São Paulo de Assunção de Luanda, 18 fev. 1767b. Biblioteca Nacional de Portugal. C 8742, F6364, fl. 148.

${ }^{14}$ COUTINHO, Francisco Inocêncio de Sousa. [Correspondência]. Destinatário: Antonio Anselmo Duarte de Siqueira. São Paulo de Assunção de Luanda, 10 abr. 1767c. Biblioteca Nacional de Portugal. C 8742, F6364, fl. 167.

${ }^{15}$ COUTINHO, Francisco Inocêncio de Sousa. [Correspondência]. Destinatário: Antonio Anselmo Duarte de Siqueira. São Paulo de Assunção de Luanda, 3 fev. 1768a. Instituto de Estudos Brasileiros/USP. Coleção Alberto Lamego, AL-083-099.
} 
Outros sobas da região entraram no conflito. Assim como aconteceu em Muxima, no presídio de Massangano, também havia um desentendimento entre sobas e moradores pelas terras da fábrica. E, mais uma vez, o governador duvidou dos moradores, ponderando que nenhum soba poderia ter feito essa negociação porque "comumente os sobas não po[dem] vender as suas terras por serem uma espécie de morgado". A ordem vinda de Luanda determinou que as terras classificadas como "baldias" deveriam ser ocupadas até que os supostos donos apresentassem "títulos" que comprovassem a "boa ou má venda", ou seja, a legitimidade dos negócios. ${ }^{16}$ Se as terras baldias tivessem dono, eles seriam obrigados a cultivá-las sob "pena de se lhes tirarem se logo o não fize[ssem]". ${ }^{17}$ Portanto, o intendente das fábricas não tinha autorização para ocupar terras produtivas.

Os sobas, de fato, reclamavam a posse de terras, e não apenas no contexto da fábrica de ferro. Em 1759, quando os jesuítas foram expulsos do Reino de Angola, seus bens foram apreendidos pela Fazenda Real. ${ }^{18}$ Entre as muitas posses dos jesuítas, foram elencadas casas, terras, arimos e fazendas que eram as propriedades com maior produção de alimentos em Luanda e seu hinterland. A posse destas terras era requerida tanto pelos moradores de Luanda e dos sertões próximos quanto pelos sobas. O governador disse que essas contestações levavam a "causas eternas", sem resolução, e sobre os sobas, registrou: "há alguns sobas que querem ter direito a muita parte delas porque sempre clamaram que [os jesuítas] as retinham em má posse e as usurparam a seus antepassados com as sutilezas e as indústrias que lhes eram naturais".19

Sobre os jesuítas e a jurisdição das terras, o governador diz ainda:

Além dos sobas há também alguns moradores que com causas eternas contendiam com eles [os jesuítas] sobre o mesmo; e igualmente a Misericórdia desta cidade, que há mais de cinquenta anos traz com eles um renhido pleito sobre a satisfação de um legado,

\footnotetext{
${ }^{16}$ Ibid.

${ }^{17}$ COUTINHO, 1767a.

${ }^{18}$ Sobre os jesuítas no Reino de Angola, segundo Catarina Madeira Santos (2005, p. 129), “a assistência missionária da Companhia de Jesus no sertão angolano, no século XVIII, foi muito pouco expressiva. Desde a restauração, em 1648, os jesuítas foram abandonando as missões do interior e passaram a ocupar-se acima de tudo do colégio de Luanda (cujas obras se iniciaram em 1607) e dos arimos (fazendas ou propriedades agrícolas) que possuíam em vários lugares, sobretudo na região do rio Bengo".

${ }^{19}$ VASCONCELOS, Antonio de. [Correspondência]. São Paulo de Assunção de Luanda, 14 de maio de 1760. AHU_CU_001, Cx. 46, D. 4261. São Paulo de Assunção de Luanda, 14 maio 1760. Arquivo Histórico Ultramarino. AHU_CU_001, Cx. 46, D. 4261.
} 
que deixou [à] dita Casa um homem de quem foram herdeiros e testamenteiros, que faleceu há cento e trinta e sete anos, importando a herança quatrocentos mil cruzados, que todos [ensoparam?] em si; e nunca satisfizeram o legado ainda depois de alcançar a Misericórdia sentenças da Relação contra eles. ${ }^{20}$

Para além do aspecto jurídico, deve-se notar que as disputas ocorriam entre os moradores de áreas sob administração portuguesa - onde predominavam representantes da elite luso-africana -, a Misericórdia e os sobas, vassalos da Coroa portuguesa que administravam de forma independente suas povoações.

Muitas observações podem ser feitas sobre este documento no que concerne aos embates pela posse de terra. Cabe sublinhar que as chefias locais requeriam há muito tempo ("sempre clamaram") a posse deste território. Como vassalos da Coroa portuguesa, as lideranças centro-africanas sabiam que o rei de Portugal e seus quadros administrativos lhes deviam a proteção, o respeito e a garantia dos seus "foros, privilégios, honras e estatutos", como registram os autos de vassalagem. ${ }^{21}$ Contudo, nem sempre eram ouvidas, e em meio a tantas tensões tiveram que legitimar conquistas e direitos por meio da confirmação de suas linhagens.

Havia um procedimento simbólico que marcava o ritual da vassalagem, uma celebração que incorporava rituais da entronização de um novo governante da cultura dos Ambundos: o undamento. Na cerimônia perpetuada pelos portugueses, undar o novo vassalo significava "deita[r] farinha (ou barro branco) sobre os ombros do chefe africano, que a esfregava pelo peito e pelos braços". Os sucessores da linhagem do soba avassalado deveriam se submeter à investidura, assim que escolhidos pelos makota, caso contrário

\footnotetext{
${ }^{20}$ Ibid.

${ }^{21}$ Os tratados de vassalagem têm sido documentos revisitados constantemente pela historiografia. Beatrix Heintze (2007) foi pioneira no estudo exaustivo deste fenômeno e dos tipos documentais que gerou. Para ela, o termo "vassalo" foi introduzido pelos portugueses no ultramar como instrumento de poder por meio do qual os chefes locais passaram "a ser vassalos do rei de Portugal num procedimento legal, documentado e reconhecido, realizado na presença de testemunhas", configurando um "tipo de dependência interestadual". Ao vencido cabia prometer cumprir todas as condições impostas, prestar juramento de fidelidade e obediência. Em contrapartida, aos vencedores cabia a "promessa de proteção e a investidura". A autora ainda diferencia a "vassalagem voluntária" - quando os chefados, por razões políticas ou econômicas, procuravam por iniciativa própria aliar-se aos portugueses - da vassalagem imposta pela força das armas. Heintze pontua, porém, que o primeiro caso era menos frequente. A regra foi a condição de vassalo ser imposta às lideranças locais, de modo que os portugueses ditavam os códigos contratuais.
} 
seriam considerados rebeldes e, portanto, passíveis de punição (HEINTZE, 2007). Assim, de parte da cerimônia, o undamento passou a ser sinônimo da própria vassalagem.

À época, uma das questões principais para o governo de Luanda era o fomento à agricultura, com o fim de combater a escassez de alimentos e a má distribuição de água. Em um bando de 1768, o governador ordenou o levantamento de todas as terras baldias ("arimos desertos") ao longo dos rios Nzenza, Ndande e Kwanza. O documento permite entender como as próprias políticas coloniais instigavam os conflitos por terras. O governador prometeu entregar as propriedades abandonadas a quem denunciasse seu estado improdutivo e se obrigasse a cultivá-las. Se, para ter acesso à terra, bastava denunciar seu mal emprego, era de se esperar que as denúncias seriam abundantes. $\mathrm{O}$ documento também informa que as terras do Reino de Angola eram ou de "natureza de sesmaria" ou "de indevidas compras aos sobas" (COUTINHO, 1768) - outra menção ao fato de que os sobas não tinham por costume vender suas terras, e que, portanto, qualquer compra de seus terrenos seria ilegal.

O regimento dos governadores ordenava que se soubesse "de todas as terras que são dadas, quem as deu, e que poder tinha para isso, e quem as possui", porque havia notícia de que terras que haviam sido doadas não estavam sendo cultivadas. Diante disso, as terras sem dono deveriam ser repartidas entre quem se obrigasse a cultivá-las dentro de cinco anos. Se os particulares não o fizessem neste prazo, elas poderiam ser passadas a outrem. ${ }^{22}$ Esse trecho remete ao que está na "Lei das Sesmarias", de 1375, compilada nas Ordenações afonsinas, manuelinas e filipinas, com algumas modificações nos textos desses registros. ${ }^{23}$

Resta saber mais sobre o que seriam as "indevidas compras" das terras dos sobas ou a "má posse" destes terrenos pelos jesuítas.

\section{Sobas e moradores}

Os moradores formam uma categoria social de difícil definição. Na documentação, constam como pessoas livres ou forras de diversa origem africanos, portugueses, luso-africanos - que vivem contíguos a fortalezas,

\footnotetext{
${ }^{22}$ REGIMENTO do Governo do Reino de Angola dado em Lisboa. Lisboa, 12 fev. 1676. Arquivo Histórico Ultramarino. Códice 544, fl. 8v.

${ }^{23}$ Instituídas no reinado de Fernando I, as sesmarias tinham por finalidade combater a diminuição da população rural de Portugal (CÓDIGO, 2004).
} 
fazendas, vilas e presídios portugueses. A historiografia atenta para o fato de que, ao longo do tempo, se constituiu, especialmente em Luanda, uma elite formada por famílias de luso-africanos independentes dos sobados. Essas elites, que controlavam canais ligados ao tráfico transatlântico, tinham fortes ligações com as elites brasílicas. Tratava-se de um grupo "muito heterogéneo e difícil de delimitar, que incluía sobretudo africanos negros (grande parte deles antigos escravos) e 'mestiços', mas também alguns brancos", como descreveu Beatrix Heintze (2005, p. 12). ${ }^{24}$

Na ocupação portuguesa na margem Oriental africana, a terra para os chefados africanos, em especial os Maraves, era propriedade coletiva - nenhum chefe a podia venderou alienar, em um padrão quese repeteentreos Ambundos.

Em Portugueses e africanos nos rios de Sena, Eugénia Rodrigues faz um longo inventário dos prazos na região do vale do Zambeze. No Índico, instituiu-se um outro enquadramento jurídico para a repartição de terras: os prazos eram "concessões enfitêuticas, em que a Coroa retinha o domínio direto e cedia o domínio útil em troca do pagamento de um foro" (RODRIGUES, 2013, p. 25). O arrendamento perdurava, inicialmente, três gerações, e poderia ser renovado. Do mesmo modo que os sobas Ambundos, os chefados dos rios Sena entraram em conflito com os colonos, que diziam ter comprado suas terras. E, neste ponto, o livro de Rodrigues pode nos ajudar a elucidar a origem dessa confusão: afinal, os moradores compravam ou não terras das lideranças locais?

No caso de Moçambique, o estabelecimento dos portugueses no território africano era selado com a oferta de panos. Na transação, "aparentemente, o chefe africano permanecia o senhor da terra, embora os mercadores dos rios considerassem que as tinham comprado ou que elas lhes tinham sido doadas". A historiadora alerta que para compreender esse enfrentamento é preciso separar os "conceitos europeus de doação e de compra" das modalidades de "granjeamento de novos súditos pelos chefes africanos" (RODRIGUES, 2013, p. 357). ${ }^{25}$

\footnotetext{
${ }^{24}$ Para o século XIX, ver Vilas Bôas (2018). Para esse autor, os moradores formavam um grupo bastante distinto, formado por africanos, mestiços e colonos brancos, todos livres e possuidores de alguma propriedade, fosse ela móvel ou imóvel. Os moradores participavam da vida política de Angola, eram vitais no andamento do comércio e tinham cargos burocráticos na hierarquia militar das milícias que atuavam nos sertões. Em certa medida os moradores constituíam a camada de intermediários entre a administração colonial e os sobados africanos. (VILAS BÔAS, 2018, p. 23).

${ }^{25}$ Rodrigues (2013) também aponta para a obtenção de terras por parte de mercadores por meio de alianças militares e matrimoniais nos territórios dos Estados Karangas, emergentes do Império Monomotapa.
} 
É válido considerar que uma confusão parecida tenha provocado os desentendimentos entre os sobas e os moradores dos presídios ao longo do rio Kwanza, visto que as relações entre eles eram pautadas por ofertas de mercadorias como os tecidos, objeto-moeda comum na África Centro-Ocidental. ${ }^{26} \mathrm{Um}$ gesto, uma negociação ou uma simples troca de presentes tinham significados distintos para os envolvidos, de modo que é possível imaginar que aquilo que para os primeiros colonos seria uma transação de compra de terras, para os Ambundos representasse uma oferta para autorizar a passagem por seu território ou celebrar uma aliança, por exemplo.

Entretanto, uma interpretação que não deve sair de nosso horizonte de pesquisa é a da desapropriação pela força, em situação de guerra, por exemplo. Segundo Jan Vansina (2005, p. 22), os sobas destituídos durante a conquista, não tendo outro recurso, negociaram suas terras com os colonos.

Voltando ao estudo de caso em questão, os moradores dos presídios no hinterland de Luanda começaram a enviar documentos-referidos nas fontes apenas como "títulos" - que poderiam comprovar a posse da terra. O governador Sousa Coutinho chegou a receber uma lista com nomes dos que alegavam ter terras entre as que foram separadas para construir a fábrica. A ordem era ressarcir os que tiveram parte de suas propriedades anexadas indevidamente à fábrica. ${ }^{27}$

Não podemos dizer o mesmo sobre os sobas, ou seja, se comprovaram a sua titularidade sobre a terra. Porém, conforme lemos até aqui, havia duas formas de lidar com os terrenos em Angola: a sesmaria, que orientava como os moradores deviam adquirir terras, e a "espécie de morgado", que regulamentava a posse africana sobre os terrenos. Como decidir em caso de sobreposição dessas normas, quando a mesma terra era reivindicada por chefes africanos e moradores? Que lei valia, a dos sobas ou das Ordenações? Além disso, qual eram as regras africanas de acesso à terra, e o que seria o tal "morgado" africano?

\section{O morgado africano}

De acordo com a historiadora Isabel de Castro Henriques, "a terra africana é abrangente, engloba todos os territórios africanos: a terra é o cosmos" e, portanto, integra o espaço sagrado: "para os africanos a terra não

\footnotetext{
${ }^{26}$ O termo objeto-moeda foi cunhado por Lovejoy (2002, p. 169-170).

${ }^{27}$ COUTINHO, Francisco Inocêncio de Sousa. [Correspondência]. Destinatário: Antonio Anselmo Duarte de Siqueira. São Paulo de Assunção de Luanda, 7 abr. 1769b. Instituto de Estudos Brasileiros/USP. Coleção Alberto Lamego, AL-083-223.
} 
é valor de troca, pois ela não pertence ao grupo senão graças à mediação dos espíritos". Dessa forma, no território africano encontram-se alguns dos "pilares fundamentais da identidade africana" (HENRIQUES, 2004, p. 40): o parentesco e a religião. As árvores sagradas, os rios, as plantas que forneciam os pigmentos das cores sagradas, os tambores que levavam mensagens de uma cubata a outra, as sepulturas dos antepassados ou dos heróis fundadores são marcadores importantes deste território. ${ }^{28}$ Por exemplo, em 1809, o capitão-mor do presídio das Pedras de Pungo Andongo ordenou a alguns sobas vassalos que fossem habitar em uma das ilhas do Kwanza. As chefias não aceitaram porque isso ia contra "os seus ritos", traduzidos pelos agentes coloniais como "leis gentílicas"29.

A ideia de "morgado" é a mais próxima que o governador Sousa Coutinho conseguiu formular para compreender a relação dos sobas com as terras da Ilamba, aproximando a noção de parentesco e transmissão de títulos de nobreza, para os africanos, à dos direitos de herança e de sucessão dos europeus. Segundo o dicionário do padre Raphael Bluteau (1728, p. 580), "morgado" ou "bens de morgado" eram "bens vinculados de sorte que sem se poderem alienar, nem dividir, o sucessor justamente os possua na mesma forma e ordem que o instituidor tem declarado".

As Ordenações Filipinas determinavam como deveria ocorrer a transferência da herança do morgado, que em primeiro lugar privilegiava o filho homem primogênito, e "posto que o filho mais velho morra em vida de seu pai, ou do possuidor do morgado, se o tal filho mais velho deixar filho, ou neto, ou descendentes legítimos, estes tais descendentes por sua ordem se preferirão ao filho segundo". ${ }^{30} \mathrm{O}$ morgado também deveria ser confirmado pelos herdeiros pela posse de um documento.

O mais importante a destacar aqui é que, ao fazer a analogia com o morgado, o governador entendia que a posse da terra era regida pelas regras do parentesco em uma "espécie" de morgado africano.

\footnotetext{
${ }^{28}$ Sobre os múltiplos sentidos da terra para os africanos, Holly Hanson (2003) apresenta um exemplo interessante. Hanson estudou como um sistema de relações sociais baseadas em "obrigações mútuas" (reciprocal obligation) foi a base do desenvolvimento do Estado de Ganda. As obrigações giravam em torno da posse de terra (que era pagamento da obrigação) e continham significados afetivos que determinavam hierarquias sociais e políticas.

${ }^{29}$ BRITO, Matias Joaquim de. [Correspondência]. Destinatário: Saldanha da Gama. [S.l.], 19 fev. 1809. Arquivo Histórico de Angola. Cód. 3018, s.fl.

${ }^{30}$ CÓDIGO Philippino, ou, Ordenações e leis do Reino de Portugal: recopiladas por mandado d'El-Rey D. Philippe I. Edição fac-similar da $14^{\text {a }}$ edição, de 1821, por Cândido Mendes de Almeida. Brasília, DF: Conselho Editorial do Senado Federal, 2004.
} 
Embora exista uma relevante historiografia para outras partes do Império português, especialmente para a América portuguesa, a Índia e a África Oriental, a bibliografia sobre os conflitos por terras para o Reino de Angola e para a África Centro-Ocidental é em geral escassa e voltada predominantemente para os séculos XIX e XX. Para os autores que tratam do tema, as regras de acesso à terra Ambunda sofreram uma mudança significativa a partir do declínio do tráfico de escravos, quando o colonialismo português se voltou de forma majoritária para as atividades agrícolas: o cultivo de mandioca, milho e índigo, além da exploração de urzela, marfim e goma. Em resposta à expansão da agricultura, de acordo com esses autores, os portugueses teriam recorrido à exploração local do trabalho dos centro-africanos. ${ }^{31}$

A documentação consultada neste artigo possibilita uma visão mais matizada do assunto, pois permite conhecer conflitos em torno da terra que tiveram como causa o controle de recursos naturais. Como frisou Mariana Candido (2015, p. 230), desde o século XVI, sob os desígnios dos direitos de conquista, em nome da guerra justa, a ocupação portuguesa influenciou a política local de distribuição e controle da terra. No decorrer do tempo, a expansão para o hinterland de Luanda se intensificou levando ao enfraquecimento do poderio dos africanos. Com o declínio do tráfico transatlântico, a posse da terra se tornou uma questão central para o colonialismo, mas ela sempre existiu.

Para as regiões ao norte do rio Kwanza, os estudos mais elucidativos sobre a posse de terra são os de Eva Sebestyén $(1993,2003)$, que tratam da transmissão da posse de terras nos Ndembu, em Ndalatando e no sobado Samba Cajú, em Ambaca $^{32}$ - região próxima ao lugar da construção da fábrica de Nova Oeiras.

Sebestyén encontrou documentos sobre disputas de terras e títulos de compra e venda guardados pelos sobas da região desde o século XVII até o XX. Trata-se de registros escritos da tradição oral usados para legitimar a posse da terra, mantendo os protocolos narrativos dos testamentos portugueses, mas com conteúdo diferente. O testador não elencava os bens e os respectivos herdeiros, mas deixava um registro de informações importantes para a sua linhagem, inclusive para defender seus herdeiros da escravização: "principalmente uma declaração validando a filiação e um registro de

\footnotetext{
${ }^{31}$ Cf. Dias (1994); Ferreira (2001); Freudenthal e Pantoja (2005); Pantoja (2001); e Venâncio (1996). Para o império português na América, ver Herzog (2015) e Mota (2015). Para a África Oriental, ver Bastião (2013); Farré (2015); e Rodrigues (2013, p. 25).

32 A autora encontrou 234 documentos, entre "testamentos, listas de sobas, demarcações, inspeções, compra e venda de terrenos, casos litigiosos dos sobas por causa da terra e poder, correspondência com a administração portuguesa e familiares, autos de vassalagem".
} 
inspeções de limites que codificam a propriedade [as terras] da linhagem" (SEBESTYÉN, 1993, p. 364).

Outra informação importante é que os documentos dos sobas, da jurisdição do presídio de Ambaca, só eram reconhecidos como autênticos se o escrivão oficial do presídio os registrasse. Logo, a administração colonial reconhecia as terras das linhagens desde que fossem atestadas por seus funcionários. Note-se a dependência dos chefes africanos em relação aos funcionários dos presídios, já que eram estes que registravam e autentificavam seus "testamentos".

Para Sebestyén, esses títulos serviam a dois propósitos. Em primeiro lugar, atendiam às "exigências portuguesas na medida em que relatavam detalhadamente os limites do sobado e os nomes dos sobados vizinhos" (SEBESTYÉN, 1993, p. 365). Ao mesmo tempo, os registros serviam para salvaguardar a história que legitimava aquela linhagem: sua origem, as migrações, o primeiro assentamento, as guerras locais, as alianças. Sempre que um novo chefe era eleito, uma nova cerimônia de vassalagem era instituída, e os limites do sobado eram reconfirmados, com a inspeção de suas fronteiras. Sebestyén divide os títulos da propriedade de terra em dois grupos: nos documentos dos Dembos predominam questões ligadas a conflitos de linhagens, vida cotidiana e política; já em Samba Cajú, sobretudo nos séculos XVIII e XIX, prevalecem narrativas sobre a demarcação, disputa, compra e venda de terras.

A delimitação dos terrenos poderia ter conotação espiritual. Em outro conjunto documental guardado pelo Arquivo Histórico de Angola, no testamento de Dom Miguel Soba Caxinda Candala, datado de 1782, lemos:

Declaro que eu testador que passando tempo e vendo que o meu povo era bastante e não tinha cômodo para agricultarem ajudou-me o dito meu amigo Soba Quitala Quia Huy a Guerrear os sobas Mucundu, e outro Ndomba, e sendo [arrasados?] deixaramme ficar as terras denominadas Ngando Acaquigy riacho, ficando o dito meu amigo Quitala naquem [aquém] e eu testador nalem [além]= Declaro eu testador que descendo com o riacho Carianga o sobredito amigo sempre naquem do dito riacho, eu nalem. Declaro que descendo até a correspondência dele riacho Carianga com o rio Mussuigi, repartindo meio a meio a Lagoa denominada Quizanga de Branca no Helho pertence a mim testador $=$ Declaro que o testador foi continuando ambos amigos repartindo a andar denominado Quiconbo, o qual pelo lado esquerdo ao Soba Luachi [Dandalla Ndungil e pelo lado direito ao Soba Calanga Riaqueta e o princípio da saída do dito andar ao sobredito amigo Quitala e o fim dela a andar a mim Testador até o rio Zé Ria Cagungo, e qual rio ficasse sendo repartido por quatro sobas, Calanga Riaqqueta, Luachi Luandalla Ndungo, Soba Quitala Quia Huy por outro nome Mucamby-Huachiy pondo as suas marcações, irmãmente, sem agravo = Declaro eu Testador que depois os dois 
companheiros sobas Quitala e Luachi ficaram naquem do Rio Zé Riacagungo passei com o meu companheiro o Soba Calanga com auto denominado Muxinda (... $)^{33}$

O documento pautado na tradição oral é difícil de decifrar. Entretanto, percebe-se que o soba descreveu as razões da migração de seu povo ("vendo que o meu povo era bastante e não tinha cômodo para agricultarem"), as guerras e alianças com outros sobas para ocupar novas terras, os riachos e rios que serviam de marcadores dos terrenos e outras marcações particulares ("pondo suas marcações").

Segundo Sebestyén (1993, p. 365), as marcas fronteiriças utilizadas eram árvores específicas, que a autora descobriu terem propriedades medicinais: "árvores com o desenho de uma cruz, pedaços de argila, pedaços de ferro, pedras" e panelas de barros, entre outros. Em rituais anuais ligados à terra, os sobas recorriam ao apoio dos seus antepassados e a entidades da água "nas margens dos rios fronteiriços para conseguirem boa colheita através da oferta às sereias, quiximbi donos dos rios, protetores da terra" (SEBESTYÉN, 2015, p. 93).

Se levarmos em conta que esses não são os primeiros escritos guardados por titulares de linhagens dessa região que chegaram ao nosso conhecimento, ${ }^{34}$ é muito provável que os sobas da antiga província da Ilamba também tivessem títulos para comprovar a posse linhageira de suas terras, e que os tenham apresentado para o governador. Há indícios disso.

É interessante observar outro caso: em 1860, o soba Quipola, de Mossamedes, reclamou a posse de terras que, segundo ele, foram ocupadas por brancos para o desenvolvimento da agricultura. O soba solicitou ao governador que lhe entregasse o "título da terra" para provar a legitimidade da propriedade diante de qualquer pessoa que lhe inquirisse sobre o assunto. O pedido endossa o argumento de que a posse da terra dos sobas precisava ser atestada pelas autoridades coloniais (CANDIDO, 2015, p. 224).

Tudo leva a crer que foi por conhecer os documentos guardados pelos sobas que o governador Sousa Coutinho usou a analogia com o "morgado", pois essa terra não poderia ser mais apropriada. Há então um intercâmbio

\footnotetext{
33 TESTAMENTO de Dom Miguel Soba Caxinda Candala. [S.I.], 15 maio 1782. Arquivo Histórico de Angola. Caixa 3465 (Avulsos) - Ambaca. Agradeço a Roquinaldo Ferreira por ter compartilhado esse documento com os pesquisadores do Centro de Pesquisa em História Social da Cultura (Cecult) da Universidade de Campinas (Unicamp).

${ }^{34}$ Há ainda, pelo menos, o Arquivo de Estado do Ndembu Kakulu Kakaenda, composto por 210 documentos trocados entre o ndembu e administração colonial, datados do século XVIII ao XX (TAVARES \& SANTOS, 2002).
} 
de práticas legais e culturais que tem de ser levado em conta, de modo a chamar a atenção para como os africanos na situação colonial, além de se subordinarem e/ou resistirem, inventaram novas práticas e elaboraram soluções para conflitos, inclusive valendo-se de normas e estratégias narrativas dos portugueses. ${ }^{35}$

\section{O desenrolar do conflito na Ilamba}

Nos documentos consultados, não há nova alusão ao citado soba Muxixi ou aos sobas de Muxima, o que indica que a disputa pelas terras não se dava apenas entre funcionários régios, moradores e autoridades tradicionais centro-africanas. A questão da posse de terras também gerava conflitos entre os próprios sobas, e entre estes e outras autoridades locais - como os ilamba. ${ }^{36}$ Isso se confirma principalmente no que diz respeito às terras da Ilamba Alta, com suas ricas minas de ferro.

Os ilamba, segundo Beatrix Heintze (2007, p. 451), eram recompensados "pelos seus leais serviços prestados com terrenos nas regiões dos [sobas] vassalos". As terras onde foi fundada a fábrica de Novo Belém eram do Kilamba Ngongue a Kamukala; ao redor de Nova Oeiras se encontravam terras do Kilamba Pedro Ambaxi; e o soba Muxixi, que reivindicava terras no Luinha, aparece em outra documentação como kilamba. ${ }^{37}$ Heintze e Vansina também

\footnotetext{
${ }^{35}$ Mary Louisie Pratt (2008, p. 7-8) se vale do conceito de transculturação para "descrever como grupos subordinados ou marginalizados selecionaram e inventaram materiais transmitidos a eles por uma cultura dominante ou metropolitana".

${ }^{36}$ Kilamba em kimbundu significa pessoa encarregada de um mester. É um título difícil de categorizar porque em diversos contextos aparece relacionado à guerra preta e à colaboração com as iniciativas coloniais. Para Virgílio Coelho (2010, p. 161), o kilamba era um sacerdote "encarregado de aplacar a fúria dos gênios da natureza". Já Cadornega (1972, v. 1, p. 246) descreve o kilamba como "capitão da guerra preta". Cadornega também associou essa chefia a origens estrangeiras, e atribuiu seu contínuo crescimento político e econômico na região às habilidades militares. Eram "odiados" pelos sobas porque ao se instalarem em suas terras supostamente tornavam-se espiões que tudo reportavam aos portugueses. Nas notícias do presídio de Ambaca encontramos algo nesse sentido: o kilamba e o kimbar, ambos agentes da guerra preta, não possuíam terras, apenas se situavam em "parte das dos sobas". Beatrix Heintze (2007, p. 126), em seu glossário, define kilamba como "oficial africano na guerra preta que gozava de especial confiança dos portugueses" - interpretação presente na fonte setecentista História de Angola, de Elias Alexandre da Silva Correa (1937, v. 1, p. 291). No Livro dos Baculamentos, os ilamba aparecem como cobradores de impostos junto aos sobas. Jan Vansina (2004, p. 196) e Roquinaldo Ferreira (2012, p. 59) identificaram essas chefias como importantes agentes do comércio de escravos.

${ }^{37}$ COUTINHO, Francisco Inocêncio de Sousa. Carta que Sua Excelência escreveu aos capitães mores de todos os presídios, e distritos sobre o undamento dos sovas, quilambas e mais potentados. São Paulo de Assunção
} 
sugerem que os ilamba poderiam se tornar sobas, com o tempo. Contudo, parece haver algum consenso nas fontes de que o kilamba, embora ocupasse parte das terras dos sobas, inclusive para melhor espioná-los para os portugueses, porém não teria seus próprios terrenos.

Os casos aqui apresentados sugerem que ao menos alguns chegaram a ter terras. Provavelmente havia ilamba - sobretudo os primeiros a se associarem aos portugueses - que se tornaram senhores de terras, de recursos naturais e de gentes, e alguns quiçá até tenham sido inseridos nos mecanismos políticos de parentesco, chegando a ser sobas. Já outros não foram tão bemsucedidos, permanecendo nos terrenos dos sobas, assim como muitos sobas menores, ou sobetas, que eram congregados nas terras de um soba mais poderoso (VANSINA, 2005, p. 8). Porém, é preciso lembrar que, de acordo com algumas fontes, os ilamba não seriam bem vistos ("odiados") pelos sobas por causa de suas práticas de espionagem e alianças com os portugueses, ${ }^{38}$ haja vista que muitos sobas podem ter sido subjugados ao domínio colonial pela ação dos ilamba, que, como já dissemos, eram os capitães da guerra preta.

As contendas em torno das terras eram "causas eternas", como citado em documento anterior. O embate pelos terrenos na Ilamba se desenrolou, e outra personagem apareceu para requerer as terras: um "negro calçado" cujo nome não foi mencionado em fevereiro de $1768 .^{39}$ É provável que fosse João Correia, que apresentou uma petição com o "título de senhor das terras em que se fundou a Nova Oeiras" para a Real Fazenda um ano depois, em fevereiro de 1769. Neste documento Correia dizia possuir uma lavoura de tabaco naquela localidade, onde também lucrara com a passagem do Luinha e do Lukala ao alugar suas canoas para que comerciantes e viajantes atravessassem esses rios. Com a povoação e o início da construção da fábrica, Correia

de Luanda, 3 out. 1770. Arquivo Histórico Ultramarino. AHU_CU_001, Cx. 55, D. 6 e 7.

${ }^{38} \mathrm{O}$ sentimento de ódio registrado por Cadornega era tão patente que nos documentos encontrados por Sebestyén uma frase é recorrente: "somos vassalos da Majestade não quer sujação [sujeição] de serviço de empacaceiro, quilamba e quimbar". Os sobas pareciam não querer que sua identidade fosse associada à dos ilamba e imbari (Sebestyén, 2015, p. 92).

${ }^{39}$ COUTINHO, 1768a. Os comerciantes nos sertões angolanos (pumbeiros ou funadores) também eram conhecidos como "negro calçado". Essas personagens compartilhavam padrões culturais e sociais com suas vítimas de escravizadas, e por isso o "sucesso de seu negócio" dependia da manipulação de símbolos que os distinguiam dos escravizados. Um destes sinais de diferenciação era o uso de calçados. Neste caso, os comerciantes passavam a ser chamados "negros calçados". Muitos se valiam do novo status social para se livrar das obrigações que deviam aos portugueses enquanto seus vassalos, negando-se, por exemplo, a prestar serviço como carregadores das mercadorias dos feirantes (FERREIRA, 2001, p. 61-63). 
relata ter perdido seus negócios, tendo grande prejuízo. Como resposta à petição, as ordens vindas de Luanda mais uma vez requeriam que fossem apresentados "os títulos em que funda o dito senhorio" e que se inquirissem a testemunhas "verdadeiras e livre[s] de toda a suspeita" para saber se as terras eram cultivadas, o quanto rendiam e em que se assentava o direito de passagem dos rios. ${ }^{40}$

Na documentação sobre as terras da Ilamba temos, portanto, poucas pistas acerca de como foram resolvidos os conflitos entre as chefias locais e os outros súditos da Coroa portuguesa. A documentação é fragmentária, prenhe de contradições e embates. Na instrução aos intendentes das fábricas de ferro, de junho de 1769, Sousa Coutinho orientou como esses funcionários deveriam regular "a dúvida das terras". O objetivo da determinação era que a fábrica não se fundasse com violência, gerando revoltas entre os africanos, moradores e negociantes (no que fracassou completamente, pelo que vimos). Para tanto, o governador reiterou que o legítimo dono deveria apresentar "seus títulos". Se alguém o fizesse, seria compensado com outras terras que estivessem livres. Se não existissem "terras livres", quem ocupou terreno alheio deveria pagar um tributo ao dono. ${ }^{41}$

De toda forma, a legitimidade da posse daquelas terras na Ilamba não parece ter sido comprovada por ninguém. O que vimos é que todas essas personagens usaram os recursos que tinham a seu alcance para provar a posse. As divergências apontam para como o governo de Luanda, ao construir a fábrica, desagradou tanto os sobas quanto os moradores dos presídios. Como este assunto não aparece novamente na correspondência sobre a edificação da povoação e da fábrica de Nova Oeiras, pode-se aventar que nem os sobas, nem os moradores, nem João Correia conseguiram provar que seus títulos eram verdadeiros, o que permitiu que a região fosse ocupada pelos planos da Fazenda Real do governo de Angola. Outra possibilidade é que eles tinham os títulos, mas não havia testemunhas para certificar a posse. Ou os funcionários régios podem ter se valido de manobras legais -

\footnotetext{
${ }^{40}$ COUTINHO, Francisco Inocêncio de Sousa. [Correspondência]. Destinatário: Antonio Anselmo Duarte de Siqueira. São Paulo de Assunção de Luanda, 27 fev. 1769a. Instituto de Estudos Brasileiros/USP. Coleção Alberto Lamego, AL-083-223.

${ }^{41}$ COUTINHO, Francisco Inocêncio de Sousa. Instrução porque se hão de governar o Intendente geral Antonio Anselmo Duarte de Siqueira na diligência que agora faz para a Nova Oeiras com os Capitães Manoel Antonio Tavares, Antonio de Bessa Teixeira e Joaquim de Bessa Teixeira a qual deve cada um guardar na parte que the é respectiva e por ela responder. São Paulo de Assunção de Luanda, 2 jun. 1769c. Instituto de Estudos Brasileiros/USP. Coleção Alberto Lamego, AL-083-254.
} 
classificar as terras como baldias, requisitar a presença de testemunhas que não foram encontradas ou não eram "verdadeiras e livres de toda suspeita" -, como uma série de resoluções com o intuito de desapropriar as terras dos moradores, dos sobas, dos ilamba, de João Correia, da Misericórdia e provavelmente das donas, ${ }^{42}$ que eram grandes proprietárias de arimos.

\section{Conclusão}

Apesar de compreender outro contexto, os estudos de Sara Berry sobre a Confederação Ashanti, na Costa do Ouro, nos ajudam a pensar alguns dos assuntos que abordamos. A autora discorre sobre a influência da administração britânica na criação da confederação, em fins do século XIX. Os agentes coloniais favoreceram a ascensão do poder de chefes africanos alinhados aos seus interesses, entregando a estes as terras da região. Essa foi uma forma de criar uma base estável para estabelecer o controle do território. Na investidura das terras, eram usados símbolos da autoridade tradicional Ashanti - os blackstools ("banquetas pretas" ornamentadas).

Berry $(2001,2002)$ mostrou como os colonizadores elaboraram um aparato legal e administrativo que incluía, reformulava (inventando novas tradições) a seu favor ou excluía o que chamavam de "direitos e costumes" nativos. A administração colonial, em Angola, também se valeu de signos de poder das lideranças africanas e da estrutura hierárquica local para exercer domínio sobre o território. Valendo-se de símbolos tradicionais, como na cerimônia do undamento, e atestando os títulos da posse africana das terras, os portugueses souberam se beneficiar das estruturas políticas africanas para manter o domínio sobre sobados ao norte do Kwanza (DIAS, 1997, p. 22).

É preciso pensar que existiam outros poderes políticos tão importantes quanto o colonial para a manutenção do Reino de Angola. Em outra direção, Kristin Mann (2007) alerta para a elaboração de leis sobre a apropriação das terras, destacando o papel central dos africanos em Lagos, na transformação dessas normas ao longo do tempo. Portanto, é preciso pensar também como os africanos reverteram a seu favor as imposições vindas da administração colonial, reelaborando normas legais para legitimar suas propriedades,

\footnotetext{
${ }^{42}$ As mulheres locais se tornavam grandes proprietárias de arimos no hinterland de Luanda quando as herdavam como a terça de antigos senhores ou por conta do falecimento do marido - europeus ou luso-africanos enriquecidos. Associando essas propriedades a outras como escravos, casas, lojas e tavernas, enriqueciam e passavam a ser conhecidas como donas. (PANTOJA, 2001).
} 
fossem terras ou escravos, conseguindo manter a terra como propriedade familiar, por exemplo. ${ }^{43}$

Para Angola, como propomos aqui, ainda é preciso reconstituir com mais vagar quais eram os preceitos que determinavam a ocupação da terra para os Ambundos e como essas regras foram incorporadas, reformuladas ou excluídas nas normas criadas pelos agentes coloniais. Sem dúvida, as chefias locais, usando instrumentos impostos pela administração colonial (os "títulos de terra" - no caso, a forma jurídica do testamento) conseguiram encontrar uma maneira de manter suas terras e sustentar a própria história e poder, mesmo diante da constante reconfiguração dos poderes locais promovida pela violência escravizadora. Isso não aconteceu sem mudanças, conflitos, apropriações e guerras, porém, é notável a forma como essas lideranças asseguraram, dentro dos limites possíveis, sua autonomia ao longo do tempo. Para isso, valeram-se de seus próprios códigos culturais, insígnias ritualísticas, além de símbolos cristãos e de muitas outras formas que precisamos estudar mais profundamente. Sebestyén (2003, p. 55), por exemplo, só teve acesso à documentação citada depois de um ritual protagonizado pelos chefes locais, porque os documentos são considerados sagrados. ${ }^{44}$ Todos os anos os registros são lidos para a liderança dos sobados e continuam a legitimar o direito das linhagens sobre as terras.

Em Angola, a vassalagem das chefias africanas permitiu que o controle do território se estabelecesse por interposta pessoa e minimizou os custos dos europeus na administração de terras, inclusive das que lhes eram desconhecidas (CANDIDO, 2015, p. 224). Isso garantiu a conquista e a ocupação, mas gerou os embates entre todas as personagens descritas aqui. Na desapropriação das terras da Ilamba, as relações de interdependência entre essas personagens afloram e nos permitem visualizar as muitas nuances do exercício de domínio político - dos sobas, dos capitães-mores, dos moradores, dos governadores.

\footnotetext{
${ }^{43}$ Para Mann, as mudanças nos usos, sentidos e modos de apropriação da terra estão no cerne da emancipação de Lagos.

${ }^{44}$ Sebestyén registra que os documentos são guardados por autoridades africanas, os sobas e dembos, e seus conselheiros. No caso dos dembos, por exemplo, os papéis ficam junto a outras insígnias de poder em um local determinado, sob a custódia de Mene Tandalla, o conselheiro ligado às tradições locais e à magia.
} 


\section{Fontes impressas}

BLUTEAU, Raphael. Vocabulário portuguez e latino. Lisboa; Coimbra: Colégio da Cia. de Jesus, 1712-1728. $10 \mathrm{v}$.

CADORNEGA, António de Oliveira. História das guerras angolanas (1680). Anotado e corrigido por José Matias Delgado. Lisboa: Agência-Geral do Ultramar, 1972. 2 v.

CÓDIGO Philippino, ou, Ordenações e leis do Reino de Portugal: recopiladas por mandado d'El-Rey D. Philippe I. Edição fac-similar da $14^{\mathrm{a}}$ edição, de 1821, por Cândido Mendes de Almeida. Brasília, DF: Conselho Editorial do Senado Federal, 2004.

MONTECÚCCOLO, Giovanni Antonio Cavazzi de. Descrição histórica dos três reinos do Congo, Matamba e Angola. Tradução, notas e índices do padre Graciano Maria de Leguzzano. Lisboa: Junta de Investigações do Ultramar, 1965.

SILVA CORRÊA, Elias Alexandre da. História de Angola. Lisboa: [s.n.], 1937. 2 v. (Clássicos da Expansão Portuguesa no Mundo).

\section{Fontes manuscritas}

ANTÓNIO DE MELO, Miguel. [Correspondência]. Destinatário: Rodrigo de Sousa Coutinho. São Paulo de Assunção de Luanda, 3 dez. 1797. Arquivo Histórico Ultramarino. AHU_CU_001, Cx. 86, D. 66.

BRITO, Matias Joaquim de. [Correspondência]. Destinatário: Saldanha da Gama. [S.I.], 19 fev. 1809. Arquivo Histórico de Angola. Cód. 3018, s.fl.

COUTINHO, Francisco Inocêncio de Sousa. Instrução que deve guardar Antonio Anselmo Duarte de Siqueira servindo o emprego de intendente geral da Fábrica do Ferro e que executaram também os capitães mores como intendentes particulares na parte que lhes é respectiva. Destinatário: Antonio Anselmo Duarte de Siqueira. São Paulo de Assunção de Luanda, 12 jan. 1767a. Arquivo Histórico Ultramarino. AHU_CU_001, Cx. 52, D. 73.

COUTINHO, Francisco Inocêncio de Sousa. [Correspondência]. Destinatário: Antonio Anselmo Duarte de Siqueira. São Paulo de Assunção de Luanda, 18 fev. 1767b. Biblioteca Nacional de Portugal. C 8742, F6364, fl. 148.

COUTINHO, Francisco Inocêncio de Sousa. [Correspondência]. Destinatário: Antonio Anselmo Duarte de Siqueira. São Paulo de Assunção de Luanda, 10 abr. 1767c. Biblioteca Nacional de Portugal. C 8742, F6364, fl. 167.

COUTINHO, Francisco Inocêncio de Sousa. [Correspondência]. Destinatário: Antonio Anselmo Duarte de Siqueira. São Paulo de Assunção de Luanda, 3 fev. 1768a. Instituto de Estudos Brasileiros/USP. Coleção Alberto Lamego, AL-083-099.

COUTINHO, Francisco Inocêncio de Sousa. Instrução que levou o capitão Joaquim de Sousa Lobo. São Paulo de Assunção de Luanda, 18 jul. 1768b. Instituto de Estudos Brasileiros/USP. Coleção Alberto Lamego, AL-083-099.

COUTINHO, Francisco Inocêncio de Sousa. Bando sobre os arimos desertos. São Paulo de Assunção de Luanda, ago. 1768c. Instituto de Estudos Brasileiros/USP. Coleção Alberto Lamego, AL-083-92. 
COUTINHO, Francisco Inocêncio de Sousa. [Correspondência]. Destinatário: Antonio Anselmo Duarte de Siqueira. São Paulo de Assunção de Luanda, 27 fev. 1769a. Instituto de Estudos Brasileiros/USP. Coleção Alberto Lamego, AL-083-223.

COUTINHO, Francisco Inocêncio de Sousa. [Correspondência]. Destinatário: Antonio Anselmo Duarte de Siqueira. São Paulo de Assunção de Luanda, 7 abr. 1769b. Instituto de Estudos Brasileiros/USP. Coleção Alberto Lamego, AL-083-223.

COUTINHO, Francisco Inocêncio de Sousa. Instrução porque se hão de governar o Intendente geral Antonio Anselmo Duarte de Siqueira na diligência que agora faz para a Nova Oeiras com os Capitães Manoel Antonio Tavares, Antonio de Bessa Teixeira e Joaquim de Bessa Teixeira a qual deve cada um guardar na parte que lhe é respectiva e por ela responder. São Paulo de Assunção de Luanda, 2 jun. 1769c. Instituto de Estudos Brasileiros/ USP. Coleção Alberto Lamego, AL-083-254.

COUTINHO, Francisco Inocêncio de Sousa. Carta que Sua Excelência escreveu aos capitães mores de todos os presídios, e distritos sobre o undamento dos sovas, quilambas e mais potentados. São Paulo de Assunção de Luanda, 3 out. 1770. Arquivo Histórico Ultramarino. AHU_CU_001, Cx. 55, D. 6 e 7.

REGIMENTO do Governo do Reino de Angola dado em Lisboa. Lisboa, 12 fev. 1676. Arquivo Histórico Ultramarino. Códice 544, fl. 8v.

TESTAMENTO de Dom Miguel Soba Caxinda Candala. [S.l.], 15 maio 1782. Arquivo Histórico de Angola. Caixa 3465 (Avulsos) - Ambaca.

VASCONCELOS, Antonio de. [Correspondência]. São Paulo de Assunção de Luanda, 14 de maio de 1760. AHU_CU_001, Cx. 46, D. 4261. São Paulo de Assunção de Luanda, 14 maio 1760. Arquivo Histórico Ultramarino. AHU_CU_001, Cx. 46, D. 4261.

\section{Referências bibliográficas}

ALMEIDA, Maria Regina Celestino de. Metamorfoses indígenas: identidade e cultura nas aldeias coloniais do Rio de Janeiro. Rio de Janeiro: Arquivo Nacional, 2003.

BASTIÃO, Maria Paula Pereira. Entre a Ilha e a Terra: processos de construção do continente fronteiro à Ilha de Moçambique (1763-c.1802). Dissertação de mestrado em História, Universidade Nova de Lisboa, Lisboa, 2013.

BERRY, Sara. Chiefs know their boundaries: essays on property, power, and the past in Asante, 1896-1996. Portsmouth: Heinemann, 2001. (Social History of Africa).

BERRY, Sara. Debating the land question in Africa. Comparative Studies in Society and History, New York, v. 44, n. 4, p. 638-668, 2002.

CANDIDO, Mariana. Conquest, occupation, colonialism and exclusion: land disputes in Angola. In: SERRÃ̃O, José Vicente et al. (org.). Property rights, land and territory in the European overseas empires. Lisboa: CEHC; ISCTE-IUL, 2015, p. 223-235.

CARVALHO, Flávia Maria de. Sobas e homens do rei: interiorização dos portugueses em Angola (séculos XVII e XVIII). Maceió: Edufal, 2015.

COELHO, Virgílio. Em busca de Kàbàsà: uma tentativa de explicação da estrutura político-administrativa do reino de Ndòngò. Luanda: Kilombelombe, 2010. 
DELSON, Roberta Marx. Novas vilas para o Brasil colônia: planejamento espacial e social no século XVIII. Brasília, DF: Edições Alva, 1997.

DIAS, Jill. Mudanças nos padrões de poder do "hinterland" de Luanda: o impacto da colonização sobre os Mbundu (c.1845-1920). Penélope, Lisboa, n. 14, p. 42-94, 1994.

DIAS, Jill. O Kabuku Kambilu (c.1850-1900). Uma identidade política ambígua. In: ENCONTRO DE POVOS E CULTURAS EM ANGOLA, 1995, Luanda. Atas... Lisboa: Comissão Nacional para as Comemorações dos Descobrimentos Portugueses, 1997, p. 15-52.

FARRÉ, Albert. Regime de terras e cultivo de algodão em dois contextos coloniais: Uganda e Moçambique (1895-1930). In: SERRÃO, José Vicente et al. (org.). Property rights, land and territory in the European overseas empires. Lisboa: CEHC; ISCTE-IUL, 2015, p. 245-254.

FERREIRA, Aurora da Fonseca. A questão das terras na política colonial portuguesa em Angola nos anos de 1880: o caso de um conflito em torno da Kisanga. In: SANTOS, Maria Emília Madeira (coord.). A África e a instalação do sistema colonial (c.1885- c.1930). Lisboa: Centro de Estudos de História e Cartografia Antiga, 2001, p. 261-272.

FERREIRA, Roquinaldo. Cross-Cultural exchange in the Atlantic World: Angola and Brazil during the era of the slave trade. New York: Cambridge University Press, 2012.

FREUDENTHAL, Ainda $\mathcal{E}$ PANTOJA, Selma (ed.). Arimos e fazendas: a transição agrária em Angola, 1850-1880. Luanda: Chá de Caxinde, 2005.

FREUDENTHAL, Ainda \& PANTOJA, Selma (ed.). Livro dos Baculamentos: que os sobas deste Reino de Angola pagam a Sua Majestade (1630). Luanda: Ministério da Cultura e Arquivo Nacional de Angola, 2013.

HANSON, Holly. Landed obligation: the practice of power in Buganda. Portsmouth: Heinemann, 2003. (Social History of Africa).

HEINTZE, Beatrix. Fontes para a história de Angola do século XVII: memórias, relações e outros manuscritos da coletânea documental de Fernão Sousa (1622-1635). Stuttgart: Franz Steiner Verlag, 1985.

HEINTZE, Beatrix. A lusofonia no interior da África Central na era pré-colonial: um contributo para a sua história e compreensão na atualidade. Cadernos de Estudos Africanos, Lisboa, n. 7-8, p. 179-207, 2005.

HEINTZE, Beatrix. Angola nos séculos XVI e XVII: estudos sobre fontes, métodos e história. Luanda: Kilombelombe, 2007.

HENRIQUES, Isabel de Castro. A materialidade do simbólico: marcadores territoriais, marcadores identitários angolanos (1880-1950). Textos de História, Brasília, DF, v. 12, n. 1- 2, p. 9-41, 2004.

HERZOG, Tamar. Frontiers of possession: Spain and Portugal in Europe and the Americas. Cambridge; Massachusetts: Harvard University Press, 2015.

HESPANHA, Antonio Manuel \& SANTOS, Catarina Madeira. Os poderes num império oceânico. In: MATTOSO, José (coord.). O Antigo Regime (1620-1807). Lisboa: Círculo de Leitores, 1993, p. 395-413. (História de Portugal, v. 4).

ITO, Alec Ichiro. Uma "tão pesada cruz": o governo da Angola portuguesa nos séculos XVI e XVII na perspectiva de Fernão de Sousa (1624-1630). Dissertação de mestrado em História, Universidade de São Paulo, São Paulo, 2016. 
KANTOR, Iris. Cartografia e diplomacia: usos geopolíticos da informação toponímica (1750-1850). Anais do Museu Paulista, São Paulo, v. 17, n. 2, p. 39-61, jul./dez. 2009.

LARA, Silvia. Palmares de Cucaú: o aprendizado da dominação. Tese para concurso de professor titular de História do Brasil, Universidade Estadual de Campinas, Campinas, 2008.

LOVEJOY, Paul E. A escravidão na África: uma história de suas transformações. Rio de Janeiro: Civilização Brasileira, 2002.

MANN, Kristin. Slavery and the birth of an African City: Lagos, 1760-1900. Bloomington: Indiana University Press, 2007.

MILLER, Joseph C. Poder político e parentesco: os antigos estados Mbundu em Angola. Luanda: Arquivo Histórico Nacional, 1995.

MONTEIRO, John Manuel. Negros da terra: indígenas e bandeirantes nas origens de São Paulo. São Paulo: Companhia das Letras, 1994.

MOTA, Maria Sarita. Apropriação econômica da natureza em uma fronteira do império atlântico português: o Rio de Janeiro (século XVII). In: SERRÃO, José Vicente et al. (org.). Property rights, land and territory in the European overseas empires. Lisboa: CEHC; ISCTE-IUL, 2015, p. 43-53.

PANTOJA, Selma. Donas de "arimos": um negócio feminino no abastecimento de gêneros alimentícios em Luanda (séculos XVIII e XIX). In: PANTOJA, Selma (org.). Entre Áfricas e Brasis. Brasília, DF: Paralelo, 2001, p. 35-49.

PRATT, Mary Louise. Imperial eyes: travel writing and transculturation. New York: Routledge, 2008.

PUNTONI, Pedro. A guerra dos bárbaros: povos indígenas e a colonização do sertão nordeste de Brasil, 1650-1720. São Paulo: Edusp, 2002.

RICUPERO, Rodrigo. A formação da elite colonial: Brasil c.1530-c.1630. São Paulo: Alameda, 2009 .

RODRIGUES, Eugénia. Portugueses e Africanos nos rios de Sena: os prazos da Coroa em Moçambique nos séculos XVII e XVIII. Lisboa: Imprensa Nacional-Casa da Moeda, 2013.

SANTOS, Catarina Madeira. Um governo "polido" para Angola: reconfigurar dispositivos de domínio (1750-c.1800). Tese de doutorado em História, Universidade Nova de Lisboa, Lisboa, 2005.

SEBESTYÉN, Eva. Legitimation through landcharters in Ambundu villages, Angola. In: BEARTH, Thomas (ed.). Perspektiven afrikanistischer Forschung: Beiträge zur Linguistik, Ethnologie, Geschichte, Philosophieund Literatur: X: Afrikanistentag, Zürich, 23-25 September 1993 (Afrikanistentage). Köln: Rüdiger Köppe, 1993, p. 363-379.

SEBESTYÉN, Eva. Os "arquivos" de sobas Ambundo: um caso transcultural dos testamentos em Angola. In: CURSO DE VERÃO DA ERICEIRA, 4., 2. Ericeira: Instituto de Cultura Europeia e Atlântica, 2003, p. 51-74.

SEBESTYÉN, Eva. O contexto cultural dos marcos de terrenos nas aldeias Ambundu/ Angola. Africana Studia, Porto, v. 24, n. 1, p. 91-106, 2015.

TAVARES, Ana Paula Tavares \& SANTOS, Catarina Madeira (ed.). Africae monumenta: a apropriação da escrita pelos africanos. Lisboa: Instituto de Investigação Científica e Tropical, 2002. v. 1. 
THOMAZ, Luís Filipe. De Ceuta a Timor. Lisboa: Difel, 1994.

VANSINA, Jan. How societies are born: governance in West Central Africa before 1600. Charlottesville: University of Virginia Press, 2004

VANSINA, Jan. Ambaca society and the slave trade c. 1760-1845. Journal of African History, New York, v. 46, n. 1, p. 1-27, 2005.

VENÂNCIO, José Carlos. A economia de Luanda e hinterland no século XVIII: um estudo de sociologia histórica. Portugal: Estampa, 1996.

VILAS BÔAS, Felipe. Portugueses, moradores e sobas em Golungo Alto, Angola: negociação e conflito em narrativas de militares (c.1840-c.1860). Dissertação de mestrado em História, Universidade Estadual de Campinas, Campinas, 2018.

Recebido: 07/03/2018 - Aprovado: 23/11/2018

Editores responsáveis pela publicação:

Iris Kantor e Rafael de Bivar Marquese 